www.jmscr.igmpublication.org

Impact Factor 5.244

Index Copernicus Value: 83.27

ISSN (e)-2347-176x ISSN (p) 2455-0450

crossref DOI: _https://dx.doi.org/10.18535/jmscr/v4i10.99

\title{
Anaesthetic Management of Bariatric Surgery by Using Combination of Low Dose Dexmedetomidine and Propofol; an Alternative to Conventional Opioids and Inhalational Anaesthetics
}

\author{
Authors \\ Dr Neha Sharma ${ }^{1}$, Dr Sanjay Kalani ${ }^{2}$, Dr Vijeta Khandelwal ${ }^{3}$, Dr Jeetendra Sharma \\ ${ }^{1} \mathrm{SR}$, Anaesthesia Department, GMC KOTA \\ ${ }^{2}$ Associate Professor, Anaesthesia Department, GMC KOTA \\ ${ }^{3}$ Assistant Professor GMC KOTA \\ ${ }^{4} \mathrm{SR}$, Department of Dermatology
}

\begin{abstract}
Obesity is increasing like an epidemic; number of bariatric surgeries is also increasing proportionately. Obese patients are very prone to develop respiratory depression and hemodynamic instability due to anatomical and physiological factors. These problems are magnified by use of opioids and most of the inhalational agents which are used very frequently in bariatric surgery. We are presenting a case report with use of alternative method -combination of low dose dexmedetomidine and propofol. This study highlights their many benefits over other established techniques of anaesthesia like reduced other anaesthetic requirement during surgery, good hemodynamic stability, better recovery profile, less analgesic use, no need of ventilator support and less physiotherapy requirement in postoperative period along with better affordability and availability.

Key words-Bariatric, Dexmedetomidine, Opioids, Propofol.
\end{abstract}

\section{Introduction}

Morbid obesity $\left(\mathrm{BMI}>35 \mathrm{Kg} / \mathrm{m}^{2}\right)$ itself and its association with difficult airway, risk of aspiration, decrease tissue oxygenation, obstructive sleep apnoea, IHD, CAD, hypertension, diabetes, inadequate post operative ventilation poses a challenge to an anaesthesiologist.

Obese patient are very prone to develop hypoxemia and need postoperative ventilator support due to use of opioids ${ }^{[1]}$.

Inhalational agent with low fat solubility i.e. desflurane is also a good choice but due to limited availability in all set ups and high cost and requirement of dedicated special vaporizer we used an alternative approach which fulfils complete anaesthetic requirement with minimum side effects for management a morbid obese patient in bariatric surgery.

We are presenting a case report of 42 yrs old morbidly obese $\left(\mathrm{BMI}>45 \mathrm{Kg} / \mathrm{m}^{2}\right)$ well educated male patient posted in our hospital for laparoscopic sleeve gastrectomy.

\section{Case Report}

Permissions obtained from the patient and Institutional ethics committee to report this case. A 42 year old male BMI $45 \mathrm{Kg} / \mathrm{m}^{2}$ [weight $105 \mathrm{~kg}$ and height $5 \mathrm{ft}$.] referred to our tertiary centre for 
laparoscopic sleeve gastrectomy. Patient was known case of hypertension from last 5 years, taking amlodipine $10 \mathrm{mg}$ O.D. On preanaesthetic evaluation patient gave history of frequent awakening in night due to difficulty in breathing. His biochemical investigations like blood sugar, lipid profile, thyroid profile and lung function test were normal. On physical examination thyromental distance was short $(<6 \mathrm{~cm})$ and MPG grade III so difficult airway management was anticipated preoperatively. We did proper counselling of patient about postoperative respiratory difficulties which may occur and explained him to do efforts for self respiration.

In OT, standard monitoring devices like NIBP, pulse oximetery, 12 lead ECG, urinary catheter, temperature probe, $\mathrm{ETCO}_{2}$, BIS were attached. Two IV lines were secured with $18 \mathrm{G}$ cannula. Patient was given premedication with inj. midazolam $0.05 \mathrm{mg} / \mathrm{kg}+$ inj glycopyrrolate $.01 \mathrm{mg} / \mathrm{kg}+$ inj.fentanyl $2 \mathrm{mcg} / \mathrm{kg}$, after this $1 \mathrm{mcg} / \mathrm{kg}$ dexmedetomidine was given slowly over 3 minutes. General anaesthesia was induced with inj. propofol $1.5 \mathrm{mg} / \mathrm{kg}$ I.V. slowly. Muscle relaxation was obtained with loading dose vecuroniun $6 \mathrm{mg}$. Patient intubated with $8.5 \mathrm{~mm}$ internal diameter endotracheal tube using a stellate and external laryngeal manipulation in a single attempt. Anaesthesia was maintained with infusion dexmedetomidine $0.7 \mathrm{mcg} / \mathrm{kg} / \mathrm{hr}$ and propofol $25 \mathrm{mcg} / \mathrm{kg} / \mathrm{hr}$. Infusion rate of both agents were set to maintain BIS 45-50. Oxygen and Nitrous oxide were given(50:50).Intermittent vecuronium $1.5 \mathrm{mg}$ was given to maintain adequate relaxation. Dexmedetomidine infusion was stopped 15 minutes prior, and propofol infusion was discontinued after completion of procedure. Local anaesthetic bupivacaine 0.5\% infiltrated on incision and drain site. After return of spontaneous respiration and proper suctioning, reversal agents (inj. neostigmine. $04 \mathrm{mg} / \mathrm{kg}+$ inj.glycopyrrolate. $002 \mathrm{mg} / \mathrm{kg}$ ) were given. Tube was deflated and patient was extubated in OT. Patient showed good self respiratory efforts as he was counselled preoperatively.
Postoperatively patient was shifted to PACU. Basic monitoring like NIBP, pulse oximetry were attached. He was supplemented with $40 \% \mathrm{O}_{2}$ with Venti mask. His vitals were stable NIBP-126/80 and pulse 90/min. No complaint of nausea, vomiting, dizziness, respiratory difficulty and any episode of hypoxia. There was no need of ventilator or Bipap support. After 6 hrs he was shifted to ward.

\section{Discussion}

Dexmedetomidine is a specific alpha 2 receptor agonist with antinociceptive and sedative property that has been approved by Federal Drug Administration for $24 \mathrm{hr}$ sedation in intensive care units. Reports indicate that it decreases anaesthetic requirement, provides analgesia and decreases analgesic use in PACU. ${ }^{[2-4]}$

Dexmedetomidine infusion is associated with significantly lower opioid requirement and increased the proportion of patients who are eligible for discharge within early postoperative days. ${ }^{[5]}$ Dexmedetomidine has half life of $2 \mathrm{hrs}$ so its analgesic effect persist in postoperative period also.

Propofol is an oil based preparation, completely metabolised in 2-4 hours in body. Having propertyes like rapid and smooth recovery, early ambulation, antiemetic, antipruritic \& bronchodilatory properties.

The short half lives of propofol and dexmedetomidine create a potential for easier titration, quicker recovery and less prolonged sedation related adverse effects like hypoxemia which is very frequent in obese patients. This combination is not only able to limit the dose of either drugs, but very stable from cardio respiratory stand point. ${ }^{[6]}$ This initial experience shows combination of these two drugs can be used safely in bariatric surgery.

In addition, dexmedetomidine with low concentration of propofol produces minimum respiratory depression, ${ }^{[7,8]}$ very less chances of post operative nausea and vomiting \& good analgesic effect. 
Individual drug, if used alone in high dose can cause various dose related side effects. Propofol alone in high dose causes prolonged awakening time, lipemia and alteration in platelet function. ${ }^{[9,10,11]}$ Dexmedetomidine alone in high dose can cause decrease in blood pressure and heart rate. ${ }^{[12]}$ With low dose combination of these two drugs, no such side effects were observed.

Combination of inhational agents (i.e. isoflurane, sevoflurane) along with nitrous oxide causes prolonged recovery time due to their high fat solubility.

Inhalational agent with low fat solubility i.e. desflurane is also very popular method in bariatric surgery but it has some limitations like unavailability in most of the set ups, high price which increases cost of surgery, need of a special vaporiser, pungent smell induced respiratory irritation and need of post operative analgesia. Its availability and affordability is a major issue in most of centres in our country.

The problem of postoperative respiratory complication in obese patient is magnified by the use of narcotics like morphine and fentanyl during surgery and postoperative period for pain control. [13] Opioids can cause pronounced respiratory depression in obese patients with obstructive sleep apnea. Opioids also increase postoperative nausea and vomiting.

In some studies, propofol-remifentanil combination was mentioned which has shown unacceptable incidence of bradycardia. ${ }^{[14]}$

In some studies, ketamine-remifentanil combination was used which was associated with hypertension and tachycardia through the operation, most probably due to the catecholamine release by ketamine. ${ }^{[15]}$ Hallucinations, unpleasant dreams, and delirium may be seen in some patients with this combination.

\section{Conclusion}

The anaesthetic management of morbidly obese patient in bariatric surgery is still a challenge specially in a centre with limited facility and patient with low affordability. Patho physiology of obesity is complex, opioids and most of inhalational agents make this worse. In our experience, we found use of combination of low dose propofol and dexmedetomidine is a better and safe technique in bariatric surgery which fulfils complete anaesthetic requirement, with good postoperative outcome.

\section{References}

1. Rawal N, Sjostrand U, Christofferson E, Dahlstrom B, Arvill A, Rydman $\mathrm{H}$. Comparison of intramuscular and epidural morphine for postoperative analgesia in the grossly obese. Influence of postoperative ambulation and pulmonary function .Anesth Analg 1984;63:583-92.

2. Arain SR, Ruehlow RM, Uhrich TD, Ebert TJ. The efficacy of dexmedetomidine versus morphine for postoperative analgesia after major inpatient surgery. Anesth Analg 2004; 98:153-8.

3. Dutta S, Karol MD, Cohen T, Jones RM, Mant T. Effect of dexmedetomidine on propofol requirements in healthy subjects. J Pharm Sci 2001; 90:172-81.

4. Thornton C, Lucas MA, Newton DE, Dore CJ, Jones RM. Effects of dexmedetomidineon isoflurane requirements in healthy volunteers. 2: Auditory and somatosensory evoked responses. Br J Anaesth 1999; 83:381-6.

5. Dholakia C, Beverstein G, Garren $M$, Nemergut C, Boncyk J, Gould JC. The impact of perioperative dexmedetomidine infusion on postoperative narcotic use and duration of stay after surgery. J Gastrointest Surg 2007;11:1556-9.

6. Gupta P, Tobias JD, Goyal S, Miller MD, de Moor MM, Noviski N, et al. Preliminary experience with a combination of dexmedetomidine and propofol infuseons for diagnostic cardiac catheterization in children. J Pediatr Pharmacol Ther 2009;14:106-12. 
7. Campbell C, Weinger MB, Quinn $\mathrm{M}$. Alterations in diaphragm EMG activity during opiate-induced respiratory depresssion. Respir Physiol 1995;100:107-17.

8. Maze M, Scarfini C, Cavaliere F. New agents for sedation in the intensive care unit. Crit Care Clin 2001;17:881-97.

9. Beule AG, Wilhelmi F, Kuhnel TS, Hansen E, Lackner KJ, Hosemann W. Propofol versus sevoflurane: bleeding in endoscopic surgery. Otolaryngol Head Neck Surg 2007;136:45-50.

10. Pascoe PJ, Ilkiw JE, Frischmeyer KJ. The effect of the duration of propofol administration on recovery from anesthesia. Vet Anaesth Analg 2006;33:2-7.

11. Cravens GT, Packer DL, Johnson ME. Incidence of propofol infusion syndrome during noninvasive radiofrequency ablation for atrial flutter or fibrillation. Anesthesiology 2007;106:1134-38.

12. Talke P, Richardson CA, Scheinin M, Fisher DM. Postoperative pharmacokinetics and sympatholytic effects of dexmedetomidine. Anesth Analg 1997;85:1136-42.

13. Javahert S,Abraham WT, Brown C, Nishi ama H, Giesting R, Wagoner LE. Prevalence of obstructive sleep apnea and periodic limb movement in 45 subjects with heart transplantation. Euro Heart $\mathrm{J}$ 2004;25:260-6.

14. Escalamado R.M., Glen MG, Mcculloch TM, Cummings CW. Peri-operative complications and risk factors in the surgical treatment of obstructive sleep apnea. Laryngoscope 1989;99:1125-9.

15. White PF. Comparative evaluation of intravenous agents for rapid sequence induction-thiopentol, ketamine and midazolam. Anaesthesiology 1982;57:279-84. 